Cretaceous deposits in Iraq, Nigeria and Venezuela ${ }^{5}$; and an Upper Eocene deposit in the United States ${ }^{5}$.

The Australian pollen grains of the Ephedra type have been found in sediments situated near Launceston, Tasmania, near Nelson, Victoria, and near Lake Frome, South Australia, that range in age from Paleocene to Eocene. Their occurrence in these sediments is extremely sparse.

IsABEL C. Cookson

Department of Botany,

University of Melbourne. Aug. 10.

1 Wodehouse, R. P., "Pollen Grains" (McGraw-Hill Book Co., N.Y.). 2 Auer, V., Acta Geog., 5, 1 (1935). Auer, V., Salmi, M., and Salminen, K., Ann. Acad. Sci. Fennicae, A, 3, 3 (1955).

$s$ Wodehouse, R. P., Bull. Torr. Bot. Club, 60, 479 (1933).

4 Thiergart, F., Jahrb. Reichsstelle f. Bodenforschung, 61, 109 (1942).

- Kuegl, O. S., Muller, J., and Waterbolk, H. Th., Geolog en Mijnbouw, 17, 49 (1955).

\title{
Lipide (Sudan Black Positive) Corpuscles in the Bovine Lens
}

DURING the course of histochemical investigations on lipides in the adult bovine lens, I observed certain sudanophilic corpuscles which do not appear to have been previously described. These bodies were dis. covered because of their intense staining with sudan black $B$ (and also with its acetylated derivative ${ }^{1}$ ), which was applied to frozen sections of thin lens slices that had been fixed in calcium chloride formol immediately after death. They are to be found in a restricted zone ( $1 \mathrm{~mm}$. or so wide in the radial direction) which lies $2-3 \mathrm{~mm}$. from the lens equator and extends a few millimetres on either side of the equatorial plane.

The bodies were present in all twenty bovine lenses examined; they lie between the lens fibres and are seemingly embedded in the cement substance, which also stains with sudan black. In equatorial sections they are found along the broad sides of the unequal hexagons which are characteristic for cross-sections of the lens fibres in this zone (Fig. 1). These corpuscles possess an ovoid form which is elongated in a direction concentric with the lens nucleus, as can be deduced by comparing their appearances in equatorial and meridional sections (Figs. 1 and 2). They vary considerably in size, with a length ranging from 2 to $15 \mu$; but the larger forms are more frequent. Prolonged staining with sudan black $B$ causes many of them to become intensely, almost homogeneously, blackened. When only lightly stained (for example, for $5 \mathrm{~min}$. in a saturated solution of sudan black in 70 per cent alcohol at room temperature) a dense outer rim and a paler central core can be discerned in these structures. When sections of the lenses were cut parallel to the plane of an equatorial tangent, many of the corpuscles were seen to contain a fine, often crenated, filament forming an incomplete circle in the peripheral zone. This filament is only occasionally evident in meridional (Fig. 2) and equatorial sections. Sometimes, minute, strongly sudanophilic granules are present in the interior of the corpuscle (Fig. 2).

Once these corpuscles had been located with sudan black, it was then possible to submit them to other histochemical and tinctorial tests. Other fat stains, such as sudan IV and Fettrot $7 B$, coloured these objects in pale shades of orange. The usual chromatin stains, including the Feulgen reaction, were negative. After applying the periodic acid - Schiff routine the corpuscles were faintly positive; the performic

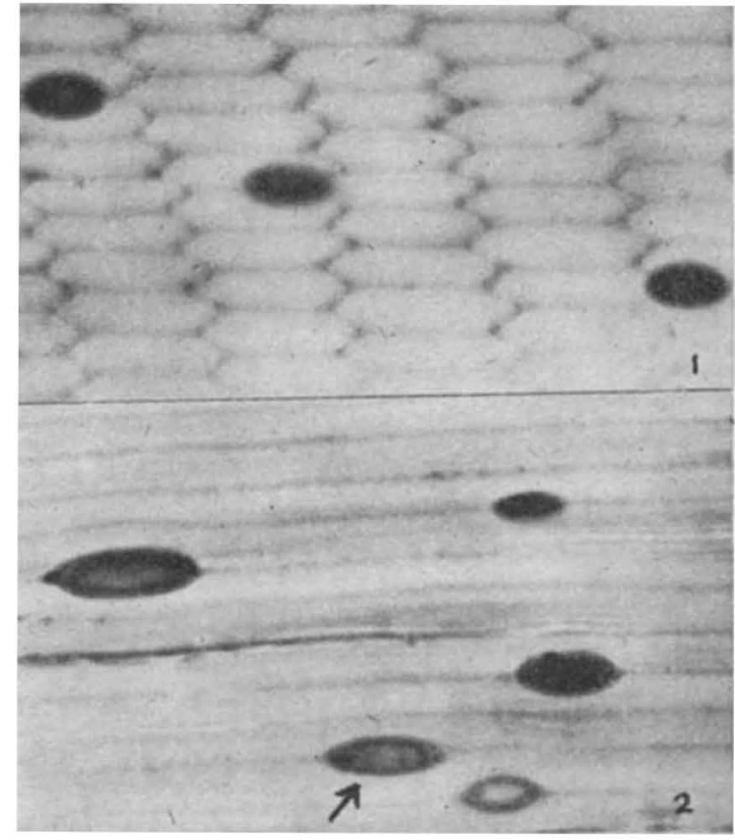

Frozen sections of the bovine lens. Fixation in calcium chloride formol. Stained with sudan black $B$. Both $\times 1,500$.

Fig. 1. An equatorial section fllustrating sudanophilic corpuscles and their relationship to the broad sides of adjacent lens 'hexagons'. The cement substance, in which the corpuscles appear to be embedded, is also sudanophilic.

Fig. 2. A meridional section. The relationship of corpuscles to the cement material and to the lens fibres is again evident. corpuscle (indicated by arrow) shows the coiled flament and minute granules described in the text

acid - Schiff technique and direct Schiff reaction were both negative.

The nature and significance of these corpuscles remains, at present, obscure. One is struck by the resemblance which they bear to nuclei; this resemblance, however, is superficial, for their morphology, tinctorial and histochemical properties, together with their location between the fibres and their situa. tion in a zone lying some distance from that of the true nuclei, all point very strongly against a nuclear relationship.

In view of the notorious ease with which artefacts can occur in microscopic sections of the lens, an attempt was made to eliminate this possibility. Fresh frozen sections of material preserved by freezing $\left(-80^{\circ}\right.$ C. $)$ immediately after death were examined with the phase-contrast microscope; the corpuscles were well seen and their relationship to the cement material again confirmed. Examination with the polarizing microscope did not reveal birefringence.

Similar corpuscles were also observed in lenses from the cat and the dog. As I have been unable to find any previous reference to these structures, I should be most grateful for comments or additional information.

Sub-Department of Histology,

A. J. DARK

Department of Anatomy,

University College of South Wales and Monmouthshire,

Newport Road, Cardiff.

Aug. 17.

' Casselman, W. G. B., Quart. J. Micr. Sci., 95, 321 (1954). 